\title{
PRE-PLANTING HARDENING-INDUCED VARIABILITY IN YIELD ATTRIBUTES AND YIELD OF INBREED AND HYBRID RICE
}

\author{
Sadia Masrufa, Anisur Rahman, Md. Hasanuzzaman, Taufika Islam Anee, \\ Md. Hazrat Ali and Mirza Hasanuzzaman* \\ Department of Agronomy, Faculty of Agriculture, Sher-e-Bangla Agricultural University, Dhaka-1207, Bangladesh \\ ${ }^{*}$ Corresponding Author: mhzsauag@yahoo.com
}

Key words: Seedling hardening, Hybrid rice, Seedling storage, Transplanted rice

\begin{abstract}
Short term hardening before transplanting may enhance the defence mechanism of rice seedlings against any stress during their establishment and contribute $d$ to enhanced growth and yield. Thus, this study was conducted involving one local inbred (Pajam), one popular high yielding (BRRI dhan53) and one hybrid (BRRI hybrid dhan4) rice variety. The experiment was laid out in randomized complete block design with two factors. Seedlings were transplanted directly to the main field as a control treatment and/or subjected to four different hardenings like seedlings storage in shade, open field under sunlight, float in water and cold air in refrigerator before transplantation. Hybrid variety out yielded both the local and inbred varieties due to their highest effective tillers, longer panicle length and 1000-grain weight. Pre-hardening of seedlings in open field under sunlight conditions enhanced the yield attributes and ultimate yield of rice compare to others. The best combination was pre-hardening seedlings in open field conditions with hybrid cultivar regarding to the yield attributes and final yields. It is suggested that hybrid variety and prehardening of seedlings before transplantation to the main field could be increase the rice yield productions.
\end{abstract}

\section{Introduction}

Rice (Oryza sativa L.) is extensively grown in all seasons of Bangladesh viz., aus, aman and boro, which covers more than $78.16 \%$ of the total cultivated area (BBS, 2014). Rice is grown under 11.385 million hectares of land with a production of 34.452 million tonnes, including aman alone in 5.53 million hectares but with a production of only 13.03 million tonnes (DAE, 2014). Proper planting and management practices are the most effective means for increasing yield of aman rice at farmer's level using inbred and hybrid varieties (Alauddin, 2004).

Though the yield of rice in Bangladesh has generally increased, it is still much lower than the genetic potential yield. However, the genetic potentiality may not be achieved due to various environmental and socio-economic conditions. This unexpected environmental conditions cause serious damage to the rice seedlings in the nursery beds and in the freshly transplanted fields. In that case, uprooting them from nursery beds can be a possible solution but it may cause loss of the vigority of seedling. As a result, aman rice cannot meet the increasing demand in the market.

Crop damage due to early or late flood is very common in Bangladesh. In flood prone areas, farmers cannot re-transplant the affected land due to unavailability of seedlings. In this case seedlings are often stored under different conditions. In many reports storage of seedlings under adverse condition showed higher vigority and yield performance under field condition. 
Rahman et al.

Seed and seedlings both undergo these conditions which are termed as priming and hardening, respectively.

The underlying mechanism(s) how seedling hardening can enhance the growth and productivity of transplanted crops may be their cross-adaptation process. Seedlings that undergone hardening increased their total sugar and $\alpha$-amylase activity and exhibited earlier initiation of protein, RNA, and DNA synthetic activity. Consequently, when the seedling is set for establishment, cellular events are much advanced (Farooq et al. 2005). Considering the above facts, it is hypothesized that the short-term adverse condition of seedling just before transplanting may induce the up regulation of defence mechanisms in plants which would be active during the subsequent episodes after transplantation to provide healthy plants with better productivity of rice seedlings.

Thus a detailed study with an inbred and a hybrid variety with some pre planting hardening of seedling treatment were undertaken to investigate the effect of seedling hardening on the performance of aman rice as well as to compare the relative performance of local, high yielding variety (HYV) and hybrid rice under different hardening treatment.

\section{Materials and Methods}

The field experiment was conducted at the Agronomy field of Sher-e-Bangla Agricultural University under the agro-ecological zone of Modhupur Tract, AEZ-28. Geographically the experimental are is located at $23^{\circ} 77^{\prime} \mathrm{N}$ latitude and $90^{\circ} 33^{\prime} \mathrm{E}$ longitude at an altitude of 8.6 meter above sea level. The farm belongs to the Shallow Red Brown Terrace Soils. The soils were clay loam in texture with pH 5.4 to5.6 and $0.82 \%$ organic carbon. Seeds of three rice genotypes (Oriza sativa L. cv. BRRI dhan53, BRRI hybriddhan4, and Pajam) were obtained from Bangladesh Rice Research Institute, Gazipur, Bangladesh. Seedlings were grown at raised seedbed for 25 days. Seedlings were uprooted the seedbed and tied in bundle and kept in different place for pre-hardening according to the treatments before transplanting to the main field. Seedlings were pre-hardened by the following treatments viz. $T_{1}=$ Direct transplanting (control), $\mathrm{T}_{2}=$ Storage in shade (seedlings kept in shade for $48 \mathrm{~h}$ ), $\mathrm{T}_{3}=$ Storage in open field (seedlings placed at normal condition under sunlight for $48 \mathrm{~h}$ ), $\mathrm{T}_{4}=$ Storage in water (seedlings float in water for $48 \mathrm{~h}$ ) and $T_{5}=$ Storage in cool air (seedlings kept in cold temperature at $4^{\circ} \mathrm{C}$ in refrigerator for $24 \mathrm{~h}$ ). The experiment was laid out in randomized complete block design (RCBD) including two factors with three replications. A basal dose of fertilizer with $\mathrm{P}_{2} \mathrm{O}_{5}, \mathrm{~K}_{2} \mathrm{O}, \mathrm{Z}$ and $\mathrm{S}$ was supplied in the form of triple super phosphate, murate of potash, zinc sulphate and gypsum. Urea was top-dressed in three equal instalments at land preparation, 30, and 50 days after transplanting. Two seedlings were transplanted in each hill maintain $25 \times 15 \mathrm{~cm}$ on the well puddle experimental plots. Intercultural operations were done whenever necessary.

The yield contributing characters such as number of effective and non-effective tillers hill $^{-1}$, number of grains panicle ${ }^{-1}$, panicle length and 1000-grain weight were recorded from plant samples. Three square meters at center of each plot was harvested, dried, threshed and adjusted $12 \%$ moisture content to estimate the grain yield. Harvest index was calculated by the following equation-

Harvest index $(\%)=($ Grain yield/Biological yield $) \times 100$. 
Pre-Planting Hardening-Induced Variability in Yield Attributes and Yield of Inbreed and Hybrid Rice

The recorded data were subjected to statistical analysis. Analysis of variance was done following two factor split plot design with the help of computer package XLSTAT 2014 and mean separation done by LSD at $5 \%$ level of significance.

\section{Results and Discussion}

\section{Genotypic differences on yield contributing attributes and yield}

Significant variation was found among the varieties regarding to the effective and noneffective tiller hill $^{-1}$, panicle length, filled and unfilled grains panical ${ }^{-1}$, 1000-grain weight. According to the Figure 1-6, BRRI hybriddhan4 produced significantly the highest effective tiller (12.07), lowest non-effective tiller $(0.98)$, longer $(26.23 \mathrm{~cm})$ panicle, highest filled grain (129.50) and unfilled grain (334.25) and highest 1000-grain weight (25.19 g). In contrast, Pajam produced the lowest effective tiller (6.48), highest non-effective tiller (2.54), shortest panicle length $(22.77 \mathrm{~cm})$, lowest unfilled grain (13.77), lowest 1000 grain weight $(17.83 \mathrm{~g})$ whereas lowest filled grain (90.19) from BRRI dhan53.

Grain yield, straw yield, biological yield and harvest index varied significantly in different varieties (Figure 7-10). The highest grain yield $\left(7.01 \mathrm{t} \mathrm{ha}^{-1}\right.$ ) was recorded by BRRI hybriddhan4 which is 58 and 54\% higher than BRRI dhan53 and Pajam, respectively. Straw yield was found in a sequence of BRRI hybriddhan4 > BRRI dhan53 > Pajam. BRRI hybriddhan4 produced $42 \%$ more straw yield than Pajam. Hybrid variety BRRI hybriddhan4 produced twice total biological yield as much as Pajam.
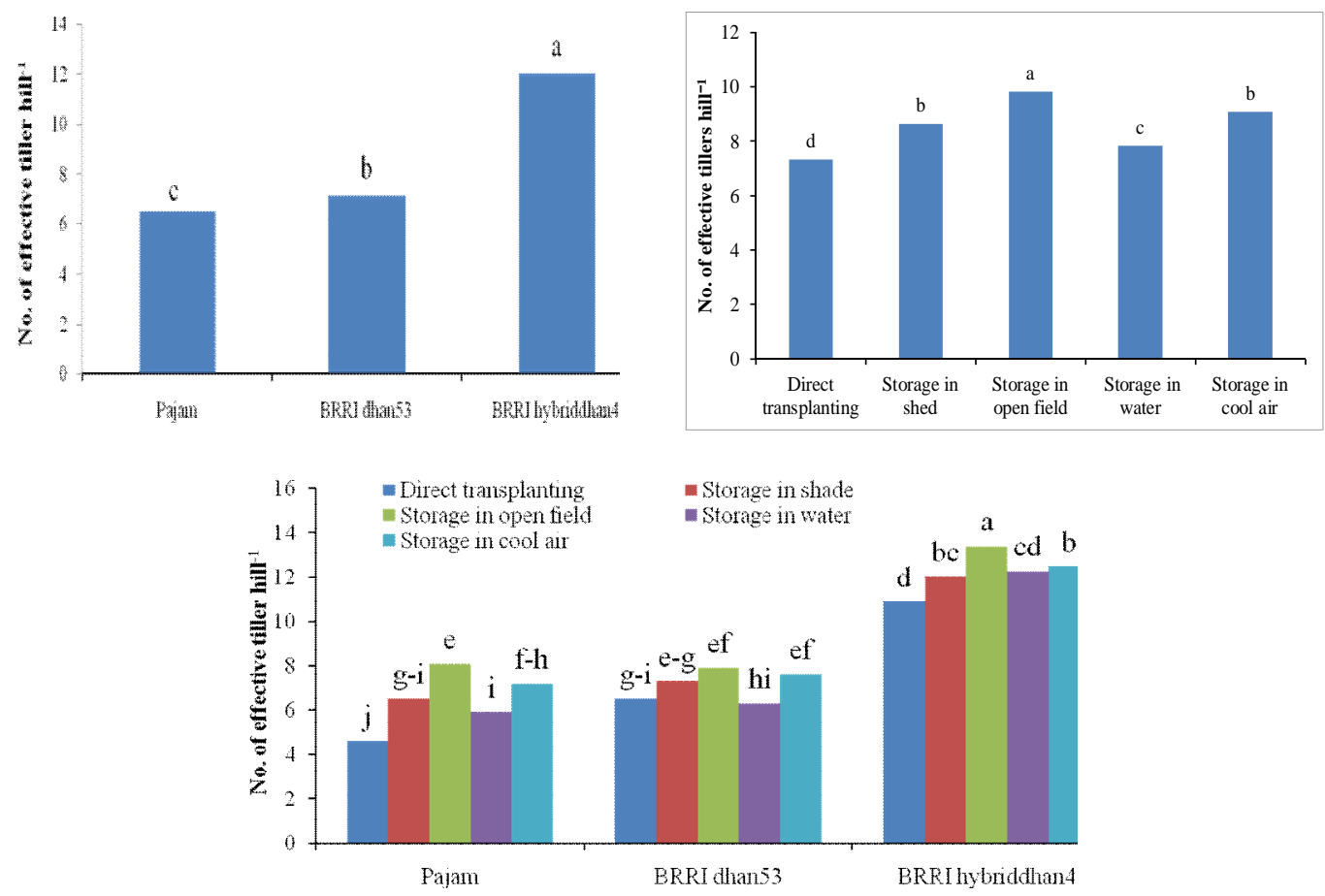

Fig.1. Effect of variety, pre-hardening of seedlings and their interactions on effective tillers hill $^{-1}$ of rice. Data labelled with different letters are significantly different at $\mathrm{P}<0.05$. 
Rahman et al.
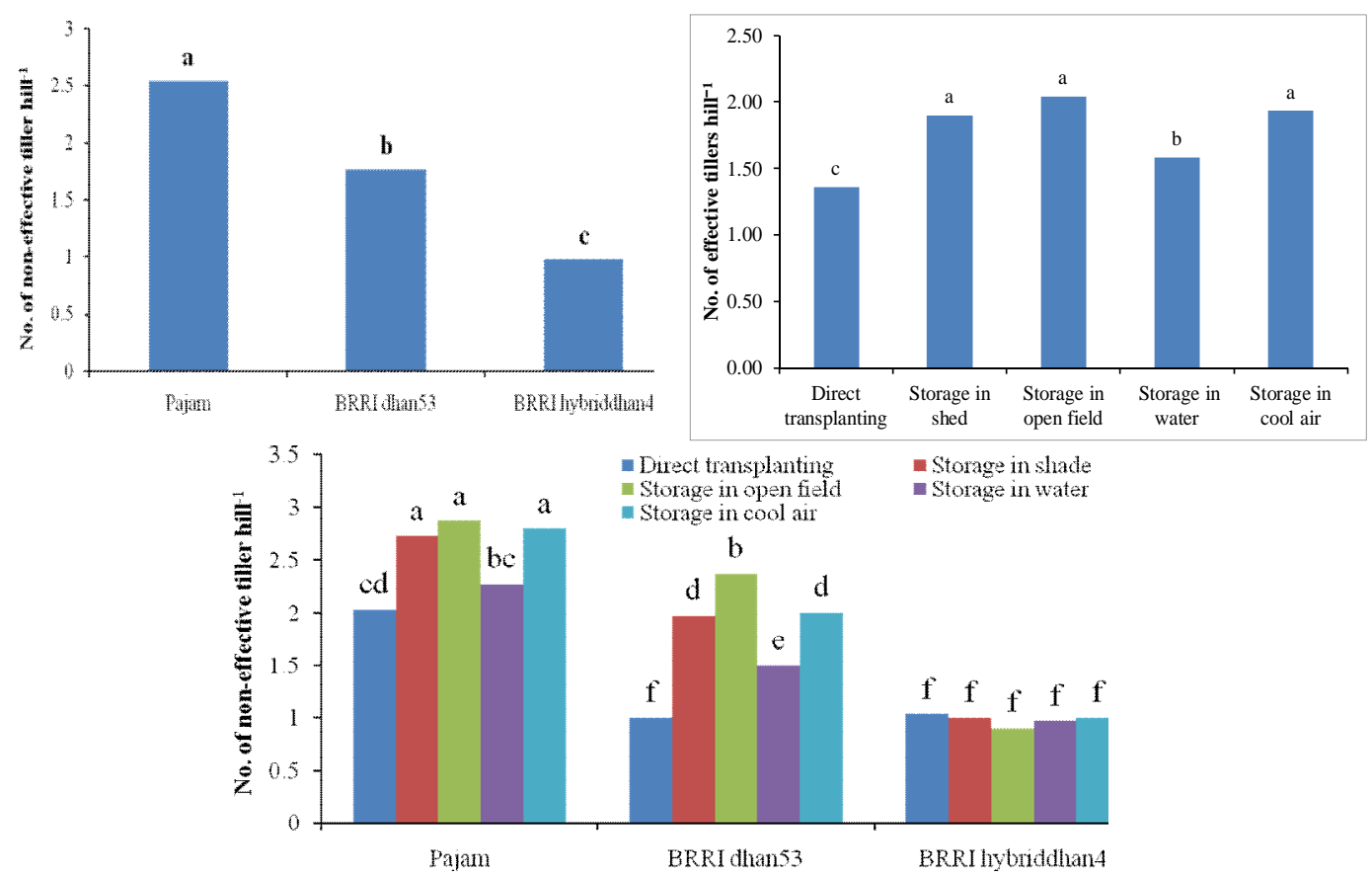

Fig. 2. Effect of variety, pre-hardening of seedlings and their interactions on non-effective tiller hill ${ }^{-1}$ of rice. Data labelled with different case letters are significantly different at $\mathrm{P}<0.05$.
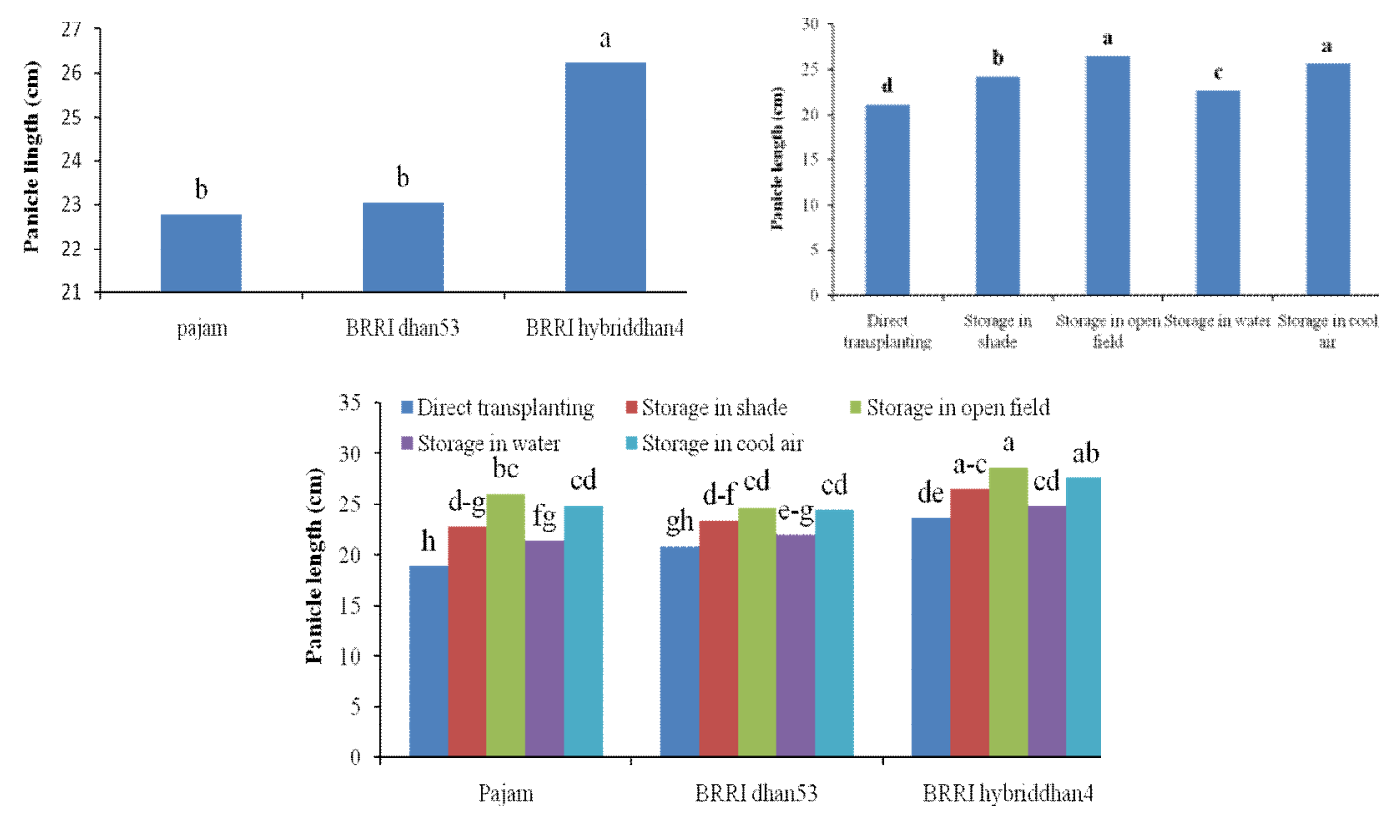

Fig. 3 Effect of variety, pre-hardening of seedlings and their interactions on panicle length of rice. Data labelled with different letters are significantly different at $P<0.05$

Influence of pre-hardening of seedling on yield attributes and yields 
Yield attributes were significantly influenced by the pre-planting hardening (Figure 1-6). Preplanting hardening under open air conditions influenced the yield attributes mostly than others compare to direct transplanting to field after uprooting the seedling from seedbed. The highest effective (9.81) and non-effective tiller (2.04), the longest panicle length (26.42 $\mathrm{cm}$ ), the highest filled (125.48) and unfilled grain (26.06) and the highest 1000- grain weight $(23.38 \mathrm{~g})$ were found from pre-planting hardening of seedling under open field storage conditions followed by storage in cool air conditions. Direct transplanting of seedling after uprooting from seedbed influenced to produce lowest effective (7.32) and non-effective tiller (1.36), the shortest $(21.12 \mathrm{~cm})$ panicle length, the lowest filled and unfilled grain $(94.86$ and 18.73 , respectively) and the lowest 1000 - grain weight $(20.64 \mathrm{~g})$ than other treatments.

Grain yield straw yield, biological yield and harvest index also influenced significantly by different pre-hardening treatments (Figure 7-10). Open field pre-hardening seedlings contributed to produce the highest grain yield $\left(4.85 \mathrm{t} \mathrm{ha}^{-1}\right)$ and straw yield $\left(4.87 \mathrm{t} \mathrm{ha}^{-1}\right)$ which is 20 and $18 \%$ higher than the direct transplanting after uprooting the seedlings from seedbed. The highest biological yield $\left(9.72 \mathrm{tha}^{-1}\right)$ was obtained from the storage in open field seedlings. Open field seedlings produced the highest grain yield and straw yield which resulted in the highest biological yield. The highest harvest index (50.32\%) was obtained from the condition of storage in cool air seedling which was statistically at par with storage in water $(49.45 \%)$ and storage in open air condition. The lowest harvest index $(47.53 \%)$ was found from direct transplanting seedlings which were statistically similar with storage in shading condition $(47.80 \%)$.

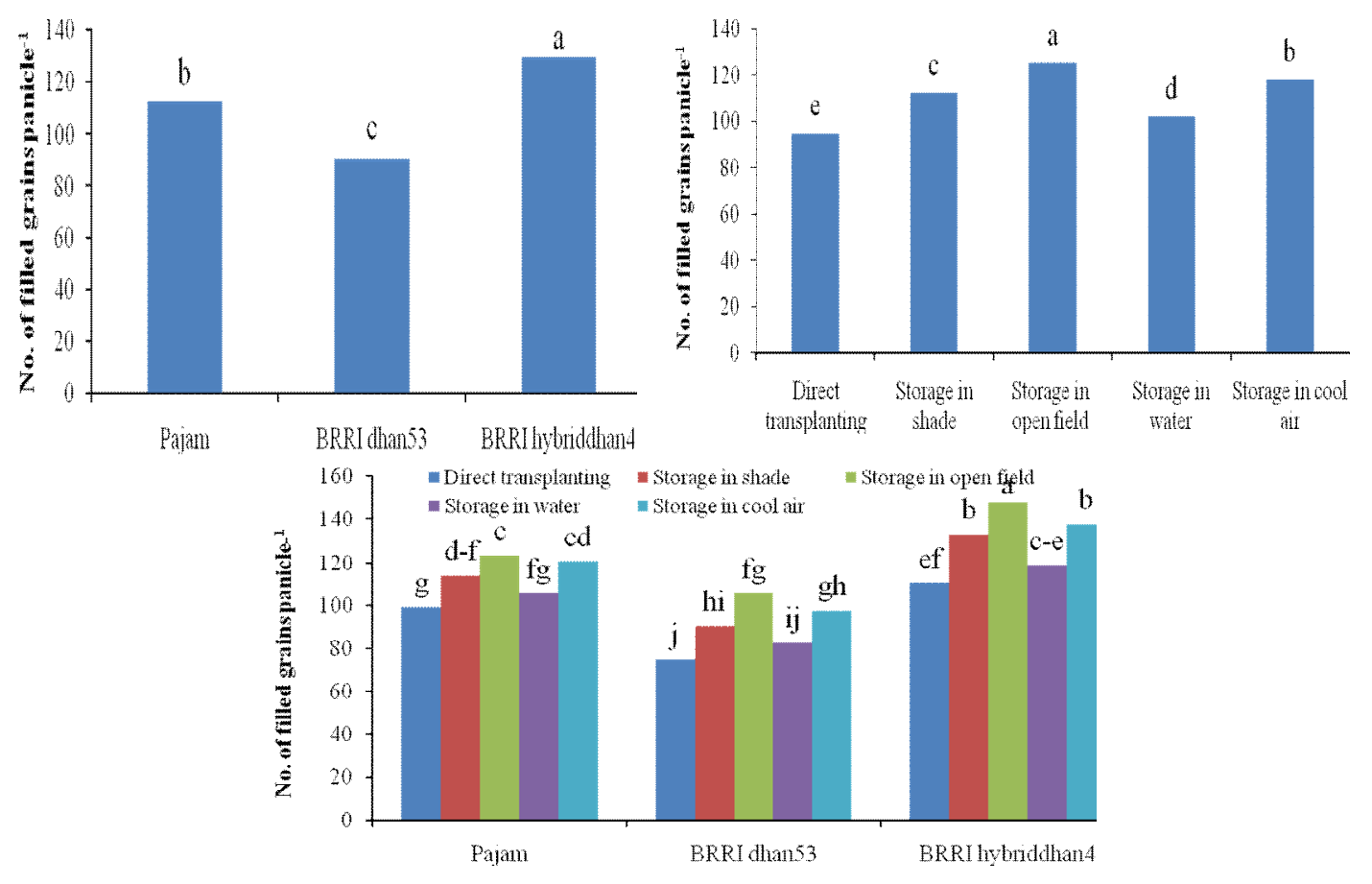

Fig.4. Effect of variety, pre-hardening of seedlings and their interactions on filled grain panicle ${ }^{-1}$ of rice. Data labelled with different letters are significantly different at $\mathrm{P}<0.05$. 
Rahman et al.

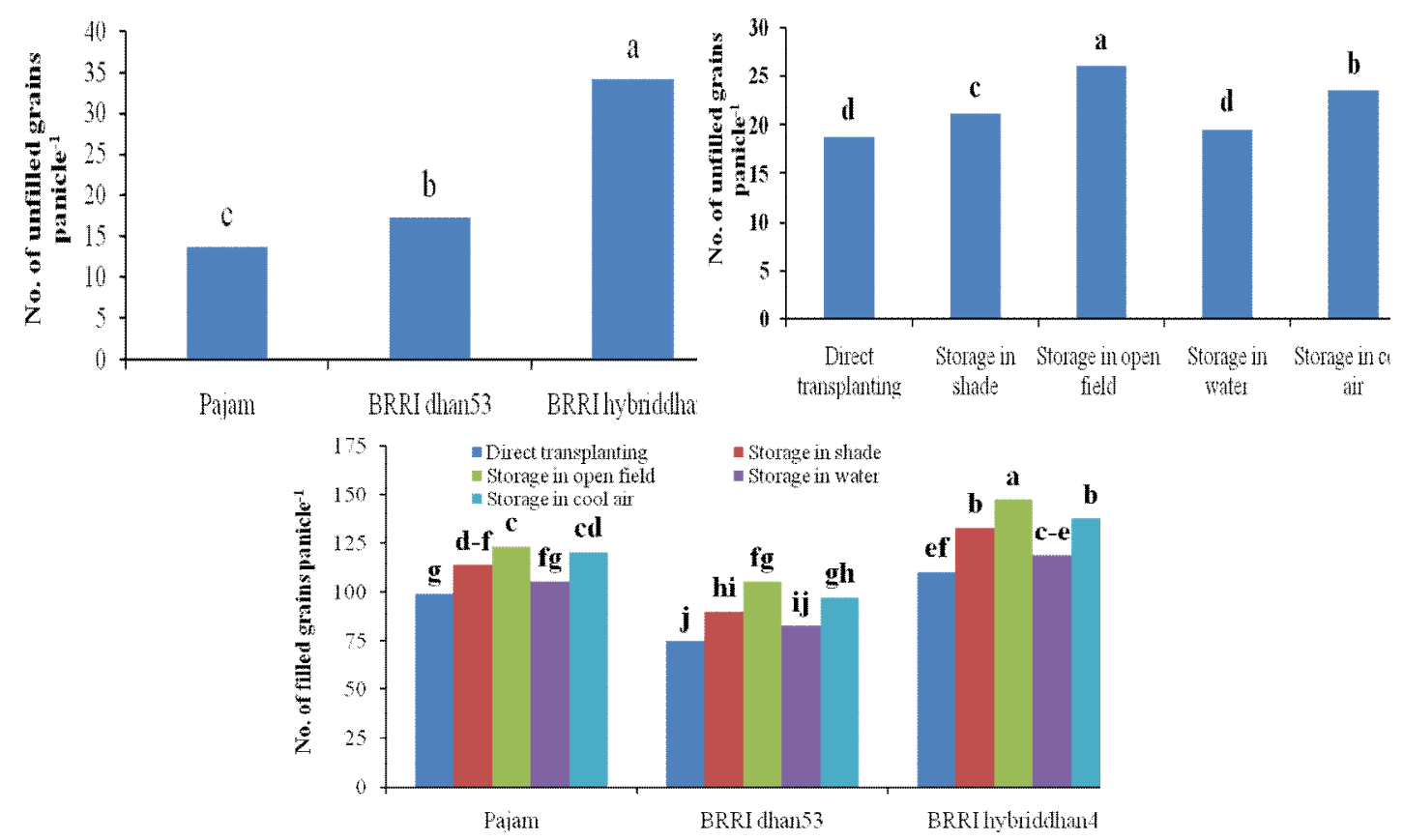

Fig. 5. Effect of variety, pre-hardening of seedlings and their interactions on unfilled grains panicle $^{-1}$ of rice. Data labelled with different letters are significantly different at $\mathrm{P}<0.05$.

\section{Interaction effect of pre-hardening treatments and rice genotypes}

Interaction effect of rice genotypes and different seedling pre-hardening treatments differed significantly in yield attributing characteristics and different yield parameters (Figure 7-10). The best combination was observed by the interaction of BRRI hybriddhan4 with seedling pre-hardening under open field storage conditions which contributed to improve all yield contributing characteristics except non-effective tiller. The combination of Pajam and open field stored seedling produced more non-effective tillers. On the other hand, the lowest filled grain (75.13) was found by the interaction effect of BRRI dhan53 with without pre-hardening seedlings which was statistically similar with seedling storage in water with Pajam variety and storage in open field and cool air treatment with BRRI dhan53. The lowest 1000-grain weight $(15.03 \mathrm{~g})$ was found with the interaction effect of Pajam with direct transplanting after uprooting from the seedbed.
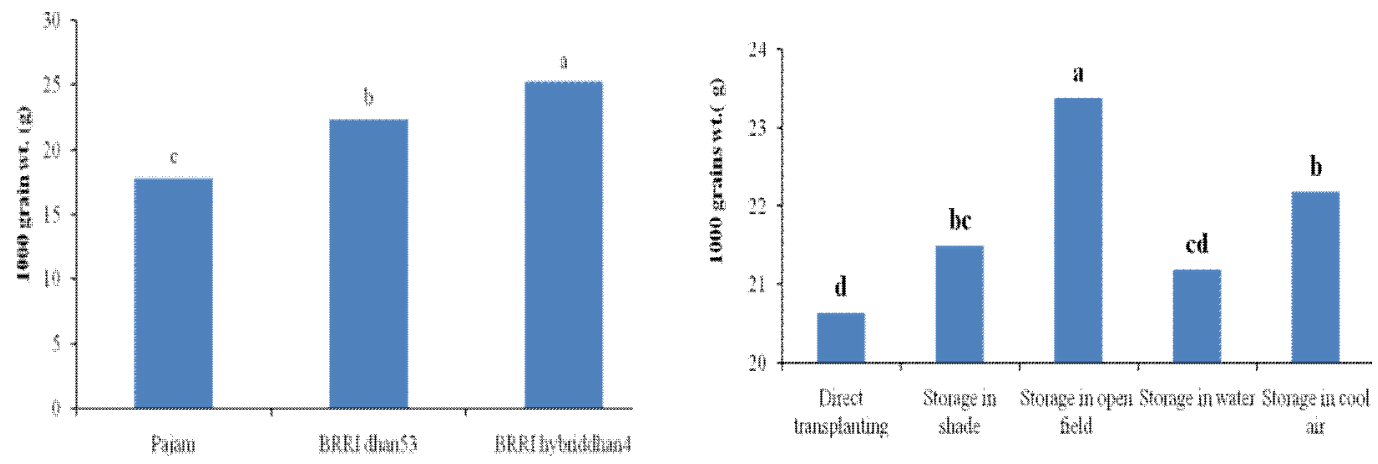
Pre-Planting Hardening-Induced Variability in Yield Attributes and Yield of Inbreed and Hybrid Rice

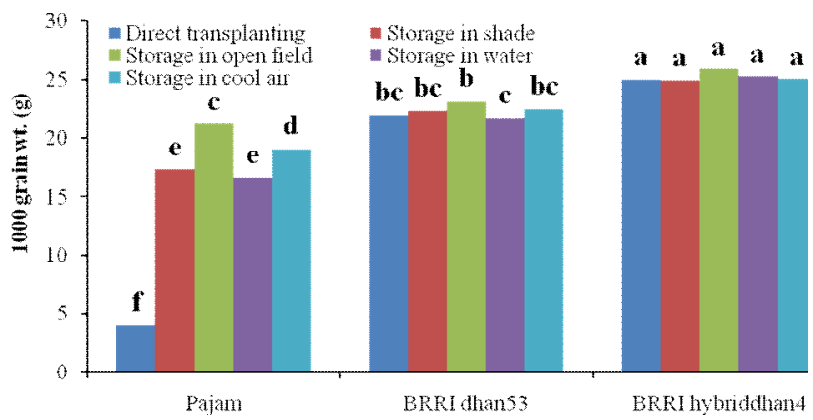

Fig. 6. Effect of variety, pre-hardening of seedlings and their interactions on 1000-grain weight of rice. Data labelled with different letters are significantly different at $\mathrm{P}<0.05$.
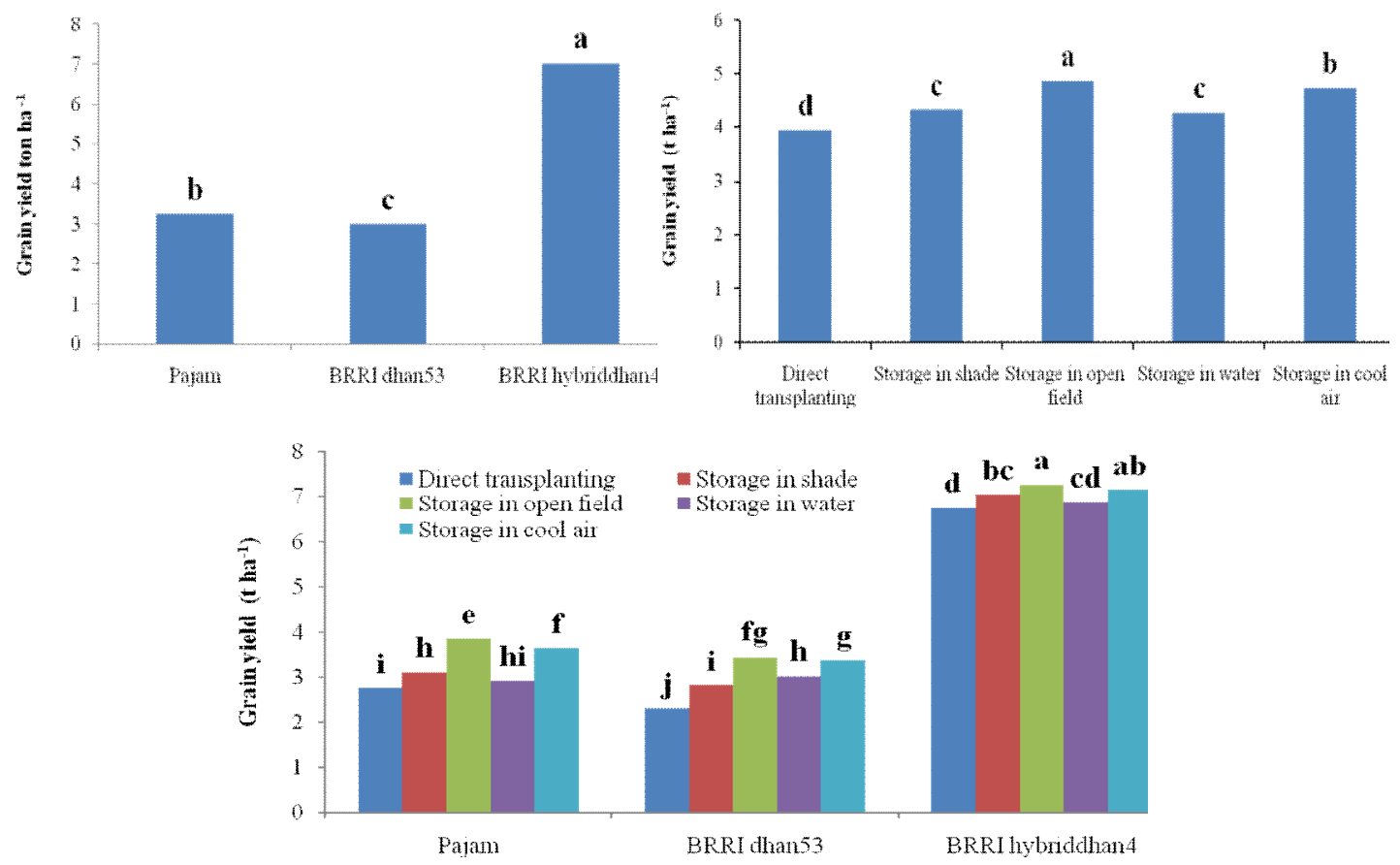

Fig. 7. Effect of variety, pre-hardening of seedlings and their interactions on grain yield of rice. Data labelled with different letters are significantly different at $\mathrm{P}<0.05$.
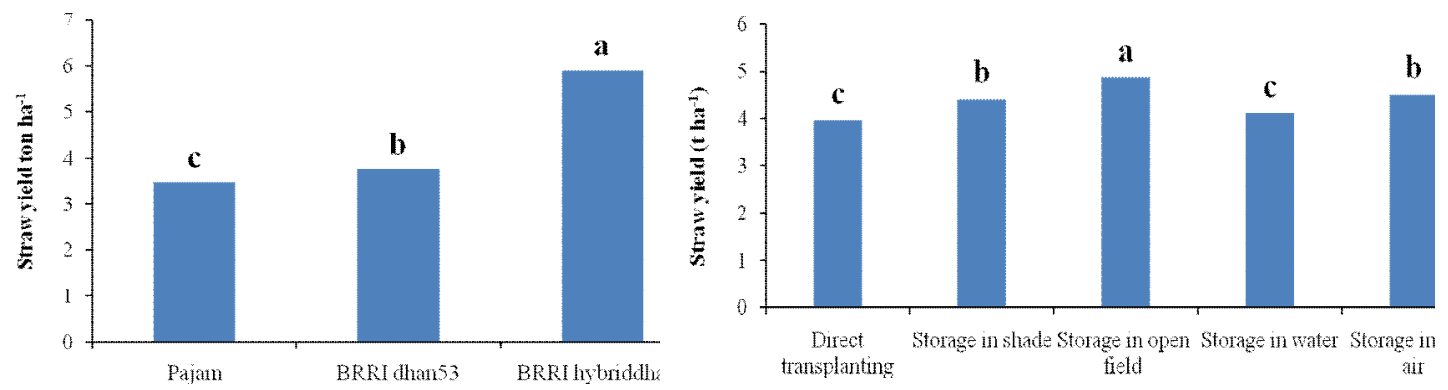
Rahman et al.

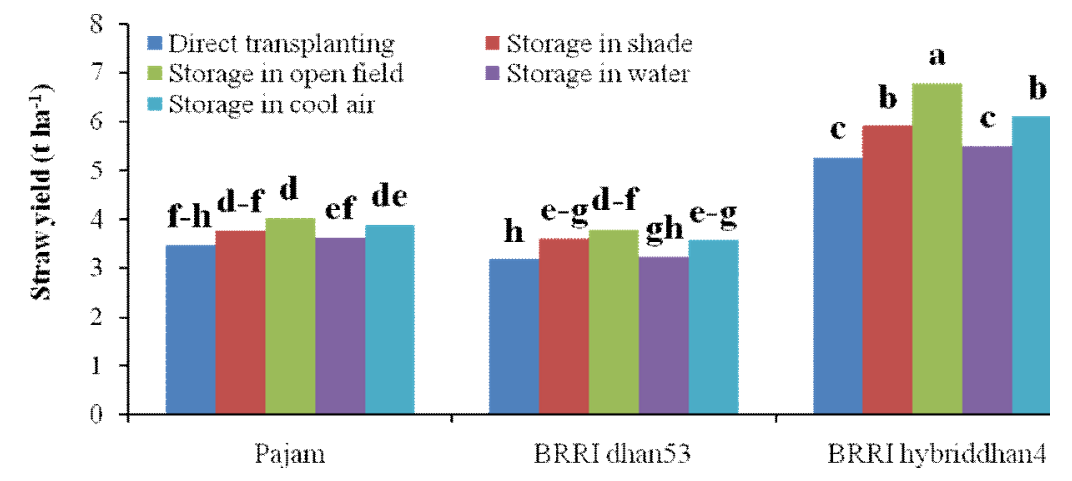

Fig. 8. Effect of variety, pre-hardening of seedlings and their interactions on straw yield of rice. Data labelled with different letters are significantly different at $P<0.05$.
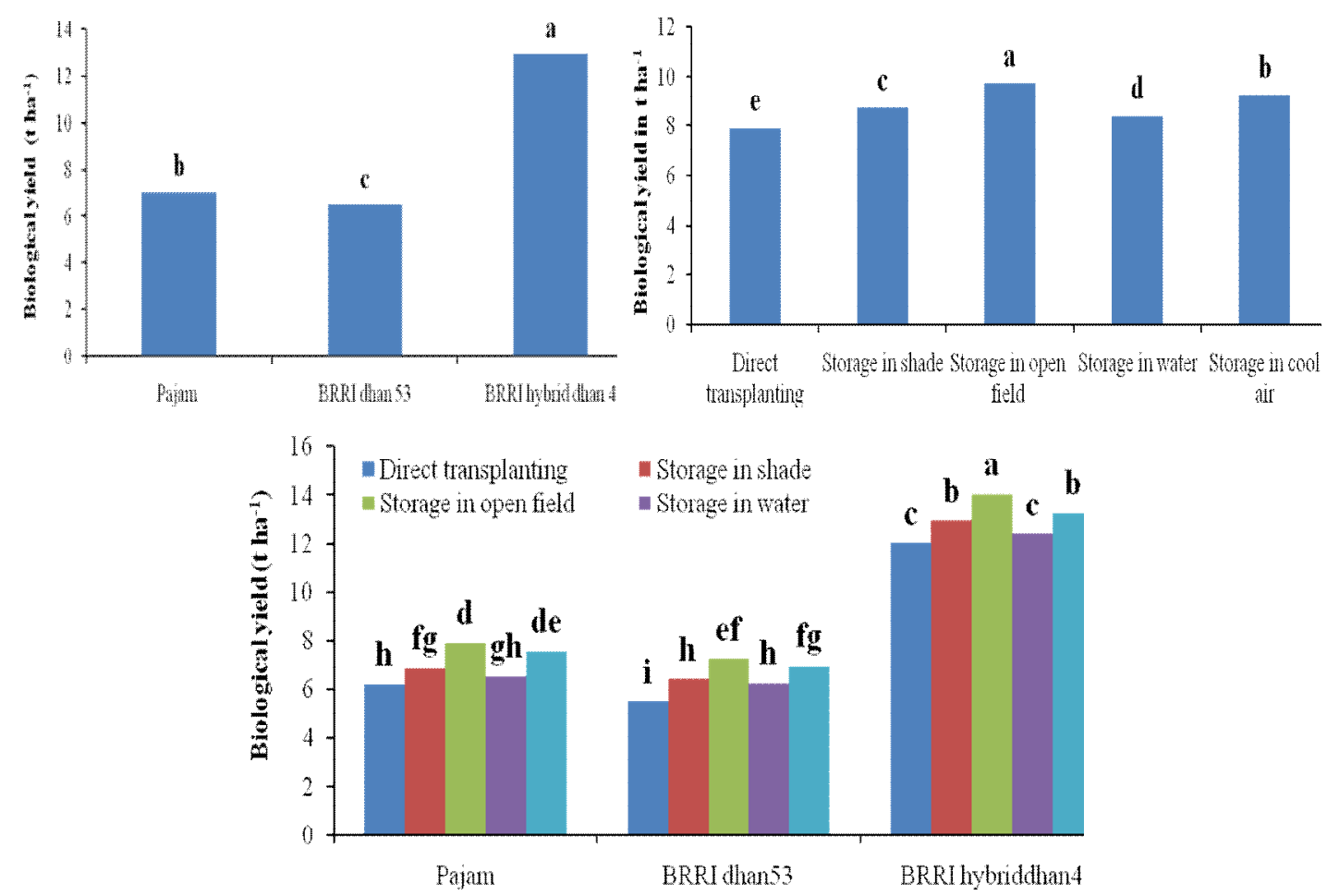

Fig. 9. Effect of variety, pre-hardening of seedlings and their interactions on biological yield of rice. Data labelled with different letters are significantly different at $\mathrm{P}<0.05$.

The maximum grain yield $\left(7.26 \mathrm{t} \mathrm{ha}^{-1}\right)$ and straw yield $\left(6.77 \mathrm{t} \mathrm{ha}^{-1}\right)$ were recorded from the interaction of BRRI hybriddhan4 and open field storage treatment condition which was statistically similar with BRRI hybriddhan4 and storage in cool air treatment. Biological yield is the combination of grain and straw yield. The maximum harvest index $(56.18 \%)$ was observed in direct transplanting seedlings of the hybrid variety, which was statistically similar with storage in water $(55.57 \%)$, storage in shade $(54.43 \%)$, and directs transplanting $(53.95 \%)$ and storage in cool air treatment of hybrid variety. 


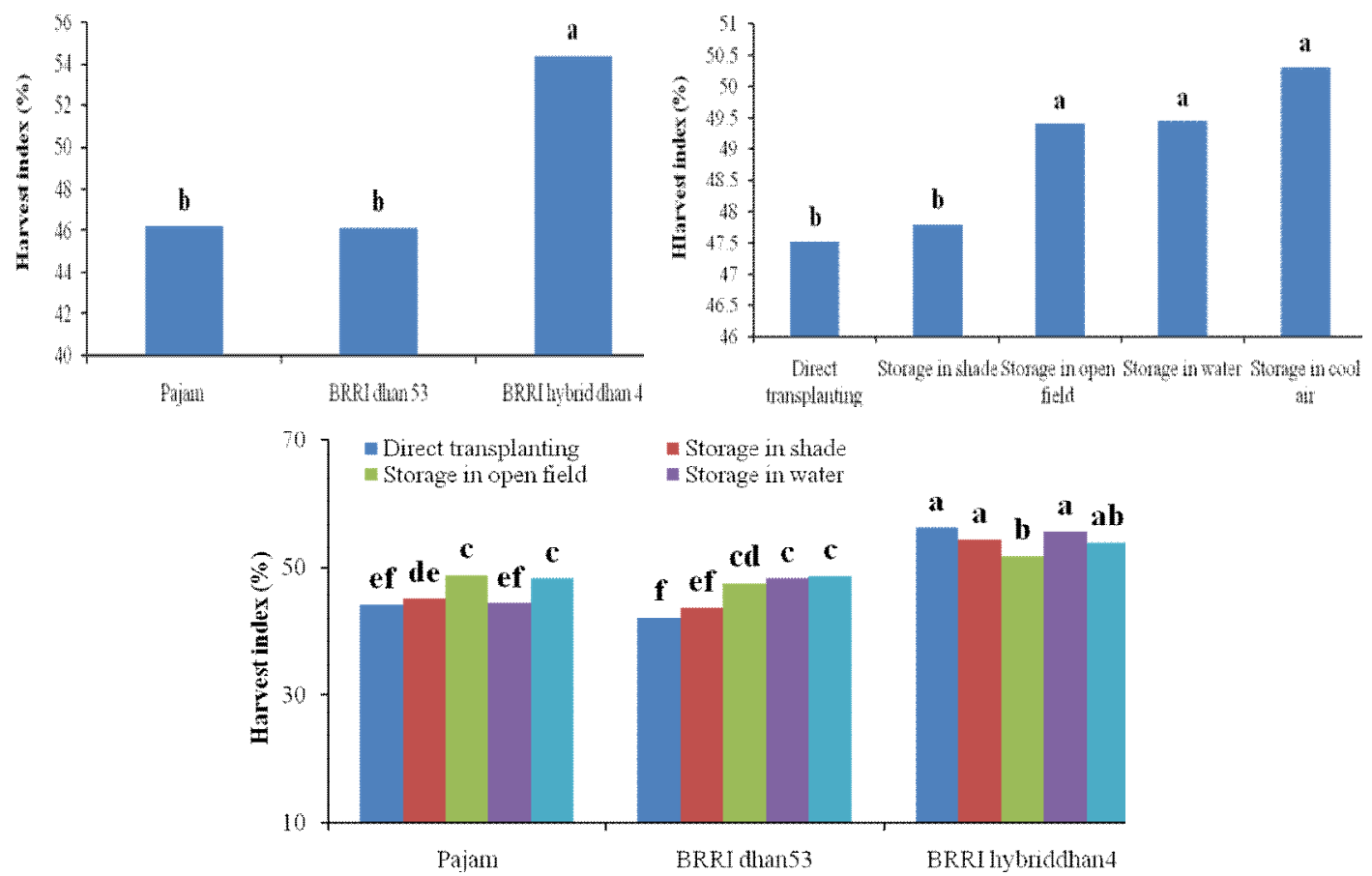

Fig. 10. Effect of variety, pre-hardening of seedlings and their interactions on harvest index of rice. Data labelled with different letters are significantly different at $\mathrm{P}<0.05$

Several pre-hardening of seedling were adapted in three rice genotypes (hybrid, inbred and local) to evaluate the varietal difference and the influence of pre-hardening of seedling on different yield contributing attributes and yields for convenient rice productions. As shown above, some of them had good predicting values and could be recommended as a good approach under unwanted situations of rice transplanting, while others showed little effect on rice productions. The possible reasons for these differences are discussed below.

\section{Hybrid varieties out-yielded the inbred}

Hybrid rice varieties exhibited higher yield and yield attributes over inbred varieties due to their inherent characteristics. Hybrid varieties have 15-30\% more yield potentiality over the inbred varieties which is the outcome of some agronomical and physiological mechanisms (Julfiquar et al., 2002 and Peng et al., 1999). Hybrid rice varieties have more photosynthesis capacity because of containing higher amount of chlorophyll in their leaf (Tang et al., 2010). In addition, flag leaf of hybrid rice contained more chlorophyll than the inbred rice genotypes which contributed to increase the photosynthesis capacity during panicle initiation (Haque et al., 2015). Higher photosynthesis potentiality of hybrid varieties attributed to accumulate higher amount of dry matter. The ultimate effect of accumulation of dry matter is to increase tiller number and vigorous growth over the inbred varieties. It has been suggested that accumulation of higher amount of dry matter before heading stage triggers the translocation of assimilated to the grain filling resulting higher number of filled grain, 1000-grain weight and ultimate yields over the modern and/or inbred varieties (Laza et al., 2003). Grain yield of rice depends on the source-sink relationship (Zhao et al., 2006). Hybrid varieties have efficient capacity to supply assimilates to the grain from the source and the capacity of the 
Rahman et al.

sink to receive it fixes the higher yield than the inbred varieties (Haque et al., 2015). The number of unfilled grain increased in BRRI hybriddhan4 than the two inbred varieties. It could be happened due to high temperature during growing season. Researcher indicated that pollen sterility increased in hybrid varieties over $33^{\circ} \mathrm{C}$ (Chakrabarti et al., 2010). In the other hand, relatively high temperature impaired slow rate of translocation of assimilated from source to sink ultimately causes higher unfilled grain in hybrid rice than inbred (Haque et al., 2015).

\section{Pre-hardening of seedling influences for more rice production than direct transplanting}

Seedlings pre-hardening under different conditions enhanced the yield and its attributes over direct transplanting of rice uprooted from seedbed before transplanting. It can be explained by the fact that under hardening conditions some physiological and biochemical changes might be happened in the seedlings for acclimatization under unwanted environmental conditions. At less stressful conditions like low temperature, short-term drought exposure often induces a variety of biochemical, physiological and enzymatic change in plant, which can result in an acclimation response. Low temperatures induce a number of adjustments in cellular components, including the extent of unsaturated fatty acids, the composition of glycerolipids, changes in protein and carbohydrate composition and increase accumulation of sucrose and other simple sugars, proline that contributes to the stabilization of membrane (Mahajan and Tuteja, 2003). It has been investigated that that short period of chilling effectively enhances the proline accumulation in plants (Habibi et al., 2011). Proline is one of the main components of defense mechanism of the plant. The accumulation of proline has a great role in protecting protein structure, redox regulation, osmotic adjustment, reactive oxygen species scavenging, and storing nitrogen and carbon for future use under less stressful conditions (Mattioni et al. 1997). Proline accumulation occurs in plant organs under any abiotic stress at a certain level and acts as a signal/regulatory compound which facilitates various physiological or molecular processes resulting increase the tolerance level of any kind of stress (Parveen et al., 2013). Pre-hardening seedlings storage under open air condition for $48 \mathrm{~h}$ and $4^{\circ} \mathrm{C}$ low temperature conditions might be induces short-term drought and old stress which helps to accumulation of compatible solutes like proline, sucrose and quaternary ammonium derivatives. Short-term stresses induction might be enhanced tolerance level of seedlings and helps to quick recovery in the main field and established growth, production of dry matter and tiller number during growth periods. More accumulation of dry matter by more photosynthesis contributes to improve yield attributing characteristics during reproductive stage of crop by the effect of source-sink relationship. The ultimate effect of increasing all yield contributing characteristics causes more yields. On the other hand, direct transplanting seedlings after immediate uprooted from seedbed take more time to establish in the field due to their root injury which affect their grow and yield.

\section{Conclusion}

In summary, hybrid variety BRRI hybriddhan4 over-yielded the modern and local inbred varieties (BRRI dhan53 and Pajam) due to higher yield attributing characters. Pre-hardening seedlings under open air for $48 \mathrm{~h}$ triggered the ultimate yield advantage over direct transplanting after uprooting from the seedbed.

\section{References}


Pre-Planting Hardening-Induced Variability in Yield Attributes and Yield of Inbreed and Hybrid Rice

Alauddin, M. H. 2004. Effect of methods of transplanting and seedlings per hill on the growth and yield of transplant aman rice cv. BRRI dhan39. M. S. Thesis. Dept. of Agron., BAU, Maymensingh, Bangladesh.

BBS (Bangladesh Bureau of Statistics). 2014. Yearbook of Agricultural Statistics, 2014.

Chakrabarti, B., P. K. Aggarwal, S. D. Singh, S. Nagarajan and H. Pathak. 2010. Impact of high temperature on pollen germination and spikelet sterility in rice: comparison between basmati and non-basmati varieties. Crop Past. Sci. 61(5): 363-368.

Farooq, M., S. M. A. Basra and N. Ahmad. 2005. Rice seed priming. Intl. Rice Res. Notes. 30(2): 45-47.

Habibi, F., H. Normahamadi, A. Sharifabad, Eivazi and M. Heravan. 2011. Effect of cold stress on cell membrane stability, chlorophyll $a$ and $b$ contain and proline accumulation in wheat (Triticum aiestivum L.) variety. Afr. J. Agric. Res. 6: 5854-5859.

Haque, M. M., H. R. Pramanik, J. K. Biswas, K. M. Iftekharuddaula and M. Hasanuzzaman. 2015. Comparative performance of hybrid and elite inbred rice varieties with respect to their source-sink relationship. Sci. World J. doi: 10.1155/2015/326802

Julfiquar, W., M. J. Hasan, A. K. Azad and A. M. Nurunnab. 2002. Research and development of hybrid rice in Bangladesh. In: Hybrid Rice in Bangladesh: Progress and Future Strategies. Bangladesh Rice Research Institute, Gazipur, Bangladesh. Pp. 9-19.

Laza, M. R. C., S. Peng, S. Akita and H. Saka. 2003. Contribution of biomass partitioning and translocation to grain yield under sub optimum growing conditions in irrigated rice. Plant Prod. Sci. 6(1): 28-35.

Mahajan, S. and N. Tuteja. 2005. Cold, salinity and drought stresses: An overview. Arch. Biochem. Biophys. 444: 139-158.

Mattioni, C., N. G. Lacerenze, A. Troccoli, A. M. DeLeonardis and N. DiFonzo. 1997. Water and salt stress-induced alterations in proline metabolism of Triticum durum seedlings. Physiol. Plant. 101: 787-792.

Peng, S., K. G. Cassman, S. S. Virmani, J. Sheehy and G. S. Khush. 1999. Yield potential trends of tropical rice since the release of IR8 and the challenge of increasing rice yield potential. Crop Sci. 39(6): 1552-1559.

Perveen, S., I. S. Kamran, J. Mehmood, M. Ijaz, R. Shafiq, A. K. Murad and J. Muhammad. 2013. Low temperature stress Induced changes in biochemical parameters, protein banding pattern and expression of Zat12 and Myb genes in rice seedling. J. Stress Physiol. Biochem. 9(4): 193-206.

Rajshekar, C. B. and A. Lafta. 1996. Cell-well changes and cell tension in response to cold acclimation and exogenous abscisic acid in leaves and cell culture. Plant Physiol. 111: 605-611.

Tang, W. B., G. L. Zhang and Y. H. Xiao. 2010. Physiological and biochemical characteristicsin flag leaves of the $\mathrm{C}$ Liangyou series of rice hybrid combinations at late growth stages. Rice Sci. 17(4): 319-325.

Zhao, B. H., P. Wang, H. X. Zhang, Q. S. Zhu and J. C. Yang. 2006. Source-sink and grain filling characteristics of two-line hybrid rice Yangliangyou 6. Rice Sci. 13: 34-42. 